\title{
BMJ Open Does parental concern about their child's future risk of overweight vary by their ethnic background? Cross- sectional analysis of a national cohort study
}

\author{
Nicola Firman, ${ }^{\circledR}$ Carol Dezateux
}

To cite: Firman N, Dezateux C. Does parental concern about their child's future risk of overweight vary by their ethnic background? Crosssectional analysis of a national cohort study. BMJ Open 2019;9:e027226. doi:10.1136/ bmjopen-2018-027226

- Prepublication history and additional material for this paper are available online. To view these files, please visit the journal online (http://dx.doi. org/10.1136/bmjopen-2018027226).

Received 12 0ctober 2018 Revised 30 July 2019 Accepted 01 August 2019
Check for updates

(C) Author(s) (or their employer(s)) 2019. Re-use permitted under CC BY-NC. No commercial re-use. See rights and permissions. Published by BMJ.

Centre for Primary Care and Public Health, Barts and The London School of Medicine and Dentistry, Queen Mary University of London, London, UK

Correspondence to

Nicola Firman;

nicola.firman@qmul.ac.uk

\section{ABSTRACT}

Objectives Children from South Asian ethnic backgrounds are at increased risk of obesity and its associated future health risks; however, evidence is lacking as to whether parental concern about their child's future overweight risk varies by ethnic background. We hypothesised that parents of 5-year-old children from South Asian backgrounds would be more likely to express such concerns.

Design Cross-sectional.

Setting UK.

Participants 15039 singleton 5-year-old Millennium Cohort Study participants (48.9\% girls; $86.7 \%$ White). Primary outcome measure Parent-reported concern (some/none) about future overweight risk.

Methods We estimated the adjusted ORs (aORs) of some parental concern (ranging from a little to very concerned) by child's ethnic background (reference group: White), adjusted for parent and child weight status, and child sex. Results Parents of girls from Pakistani (a0R 0.4; 95\% Cl 0.2 to 0.5$)$, Bangladeshi $(0.3 ; 0.2$ to 0.5$)$, Black African (0.5; 0.3 to 0.7$)$ and Mixed ( $0.7 ; 0.5$ to 0.99$)$ ethnic backgrounds and of boys from Pakistani ethnic backgrounds $(0.6 ; 0.4$ to 0.9$)$ were less likely to report concern about their child's future overweight risk than parents of White girls and boys, respectively. Overweight (2.5; 2.2 to 2.8 ) and obesity $(6.7 ; 5.7$ to 7.9$)$ in children, and overweight $(1.4 ; 1.2$ to 1.5$)$ and obesity $(1.9 ; 1.7$ to 2.2) in parents, were associated with increased likelihood of concern.

Conclusions Parents of children from South Asian ethnic backgrounds express less concern about their child's future overweight risk. Qualitative studies are needed to understand the concerns of parents from different ethnic backgrounds to inform weight-management interventions in ethnically diverse populations.

\section{INTRODUCTION}

In England, more than a quarter of children currently leave primary school with a body mass index (BMI) indicating they are overweight or obese, at a level needing clinical weight management support. ${ }^{1}$ These proportions vary by ethnic background and, after
Strengths and limitations of this study

- We used robust statistical methods to analyse a large, nationally representative cohort of children from diverse ethnic backgrounds, allowing examination of parental concern across 10 ethnic groups.

- We adjusted for factors known to be associated with increased parental concern, including child weight status, using clinical definitions of overweight and obesity, and applied ethnic-specific body mass index (BMI) adjustments for more accurate assessment of body fatness in children from South Asian and Black backgrounds.

- We were unable to apply adjustments to the BMI of children from Mixed and Other ethnic backgrounds because validated algorithms to adjust BMI among children from these groups are not available.

- Responses to the parental concern question are unlikely to be influenced by the study child weight measurement as weight was recorded after this question was answered and no interpretation or categorisation of BMI was provided to parents. As our study was cross-sectional, we are unable to determine the temporal association between concern and weight status.

- Some children may have been weighed prior to interview at home, or in clinic, schools or other settings, and this might have influenced parental concern; however, this information was not available.

adjustment to account for ethnic variation in body fat mass, are significantly higher among children from South Asian backgrounds, especially boys. ${ }^{2}$ This has important implications for their future health, as children from South Asian backgrounds are known to be biologically more susceptible to the harms of overweight, and are at higher risk of developing type 2 diabetes and cardiovascular disease in adulthood. ${ }^{3-5}$

It has been suggested that parental concern about their child's current weight status ${ }^{6}$ and 
about their child becoming overweight in the future ${ }^{7}$ may be meaningful predictors of willingness to engage in behaviour change.

Among parents of children whose BMI is in the overweight or obese range, there is evidence of increased parental concern about both their child's present weight status $^{8-11}$ and about their child becoming overweight in the future ${ }^{12}$ relative to those whose children have a healthy weight BMI. Furthermore, it has been shown that parents express higher levels of this concern about current $^{1314}$ and future ${ }^{1516}$ weight status for daughters with overweight or obesity than for sons, ${ }^{13-16}$ as well as if they themselves have a BMI categorised as overweight or obese. ${ }^{12} 16$ There is only very limited evidence regarding ethnic variation in parental concern, with lower levels of concern for current childhood overweight reported in one study of parents from Black Somali backgrounds living in Liverpool, ${ }^{8}$ and greater concern about future child overweight from another study of parents from Black Afro-Caribbean backgrounds living in London, ${ }^{17}$ with others reporting no ethnic differences. ${ }^{12}$

However, these findings are based on regional studies with low response rates and consequently small sample sizes. Moreover, none adjusted BMI for ethnicity and few specifically examine parental concern about future child overweight (as opposed to current child weight status), warranting further investigation.

Across the UK, children's heights and weights are measured on or shortly after entry to primary school at age 5 years. Following measurement, parents receive a feedback letter informing them of their child's weight status. Given the longitudinal evidence that obesity at the beginning of primary school strongly predicts obesity on leaving primary school, ${ }^{18} 19$ age 5 may be viewed as an appropriate time to intervene to prevent and tackle obesity. It is therefore important to understand how parental concern about future childhood overweight might relate to weight status at this point in the life course.

We used cross-sectional data from a large ethnically diverse UK-wide cohort study to examine whether parental concern about their child's future risk of overweight, reported when the child was aged 5 years, varied by ethnic background. Given the high rates of overweight and obesity observed among children from South Asian backgrounds after adjustments for body fat, ${ }^{2}$ and having taken parent weight status and child sex into account, we hypothesised that parents of overweight and obese children from South Asian backgrounds would be more concerned about their child becoming overweight in the future relative to parents of overweight and obese children from White backgrounds.

\section{MATERIALS AND METHODS}

\section{Study design}

We used data from the Millennium Cohort Study (MCS), a prospective nationally representative cohort of children born between September 2000 and January 2002 in the
UK, which used a stratified clustered sampling design to over-represent children born in disadvantaged areas, from ethnic minority groups or from Northern Ireland, Scotland and Wales. When the cohort child was aged 9 months, $18552(68 \%)$ of 27257 families contacted were interviewed at home when demographic, social and health information was obtained. An additional 692 families were recruited at age 3 . Further interviews were conducted when children were aged $3,5,7,11$ and 14 years, when height and weight were measured. At age 5 , $15246(85.8 \%)$ of 17770 families eligible for interview were interviewed, providing data for 15459 children (online supplementary figure S1).

\section{Inclusion and exclusion criteria}

We included 15039 of 15459 singleton children whose parent (natural mother $(97.0 \%)$, else child's main care-giver, all referred to hereafter as the parent) was interviewed when their child was aged 5 years, having excluded 418 twins and triplets, as well as two children with extreme height and/or weight measures at age 5 or missing ethnicity (online supplementary figure S1). We extracted information available for these children from their two earlier and two subsequent MCS interviews. Characteristics of those who did and did not participate in the age 5 interview are given in online supplementary table S1; participating children were more likely to be from families in the highest income quintiles and to have more highly educated mothers compared with non-participating children. We weighted all analyses to take account of survey design and to allow for potential ethnic and socioeconomic biases in cohort attrition by age 5 years.

\section{Main outcome measure}

The main outcome measure was parental concern about their child's future risk of becoming overweight. This was assessed at the age 5 interview from responses to a question administered by a trained interviewer who asked the parent "How concerned are you about [child's name] becoming overweight in the future?" We followed the methods applied by others ${ }^{1214-16}$ and derived a binary variable from the five possible responses as follows: parents reporting they were unconcerned $(n=10964)$, were categorised as 'no parental concern', with all other responses (a little concerned $(n=2645)$, concerned $(n=540)$, fairly concerned $(n=390)$, very concerned $(n=418))$ categorised as 'parental concern'. Response to this question was missing for 82 parents.

\section{Main exposure variable}

Ethnic background of the child was obtained from parental report at the first MCS interview and categorised using UK 2011 Census categories. Analyses were based on 10 individual Census categories, with the exception of some analyses where individual ethnic groups were too small to create $95 \%$ CIs when categories were grouped as follows: White (Irish, Traveller, Other), South Asian (Indian, Pakistani, Bangladeshi), Black (Black Caribbean, 
Black African, other Black), Mixed and Other (Other Asian, Chinese, Mixed, Other).$^{20}$

\section{Covariates}

We examined two covariates: child weight status and parental weight status. At age 5 years, trained interviewers in the home measured the child's height and weight: height was recorded to the nearest millimetre using a Leicester Height Measure Stadiometer (Seca, Birmingham, UK) with the head positioned in the Frankfort plane. Children were weighed barefoot and without outdoor clothing on Tanita HD-305 scales (Tanita, Middlesex, UK) and weight recorded in kilograms to one decimal place. ${ }^{21}$

To enable comparison with the current English child measurement programme, we used published guidance from Public Health England ${ }^{22}$ to assess the quality and range of height and weight measurements. We excluded one child with extreme short stature, and in addition assigned measurements in two children with extreme weight values as missing, as these were assumed erroneous when compared with their earlier or subsequent MCS weight measurements.

BMI at age 5 was calculated and adjusted for ethnicity using methods described by Hudda et al who used similar ethnic categories to those employed in this study. ${ }^{23}$ The authors pooled data from four UK studies which used the deuterium dilution method to measure body fat in approximately 2000 children from White European, South Asian and Black African backgrounds. They derived a height-standardised fat mass index (FMI) to represent body fat and fitted linear regression models to quantify ethnic differences in BMI-FMI relationships to provide ethnic-specific BMI adjustments. This adjustment entails adding approximately $1.1 \mathrm{~kg} / \mathrm{m}^{2}$ to the BMI of children from South Asian backgrounds, and subtracting between $-0.12 \mathrm{~kg} / \mathrm{m}^{2}$ and $-5.52 \mathrm{~kg} / \mathrm{m}^{2}$ dependent on sex, age group and unadjusted BMI to the BMI of children from Black backgrounds to more accurately reflect adiposity in these groups, since it has been shown that BMI overestimates and underestimates body fat in children from Black and South Asian backgrounds, respectively. No adjustment is available to apply to children from Mixed or Other ethnic backgrounds.

We categorised the adjusted BMI, according to the UK90 clinical reference standard, ${ }^{24}$ into four mutually exclusive groups: 'underweight' (BMI $<2$ nd centile), 'healthy weight' ( $\geq 2$ nd to $<91$ st centile), 'overweight' ( $\geq 91$ st to $<98$ th centile) or 'obese' ( $\geq 98$ th centile) based on alignment with sex-specific and age-specific BMI centiles from the LMS growth tool Excel add-in. ${ }^{25}{ }^{26}$ We defined those with BMI $\geq 98$ th centile or $\geq 91$ st to $<98$ th centile as clinically obese and clinically overweight, respectively. The UK90 clinical reference standard uses higher thresholds to define overweight and obesity compared with the UK90 population reference standard, indicating the need for clinical support for weight management. These thresholds are used by a variety of health professionals to assess individual children, as opposed to the UK90 population thresholds which are used to monitor population prevalence of overweight and obesity. ${ }^{24}$

Parental BMI was calculated using the parent's self-reported weight (at the age 5 sweep) and their most recent self-reported height (usually recorded at the first contact sweep). Trained interviewers measured parental heights and weights objectively if they did not know their measurements for self-report. Parental BMI was categorised into four mutually exclusive groups: 'underweight' (BMI $<18.5 \mathrm{~kg} / \mathrm{m}^{2}$ ), 'healthy weight' ( $\geq 18.5$ to $<25 \mathrm{~kg}$ / $\mathrm{m}^{2}$ ), 'overweight' ( $\geq 25$ to $<30 \mathrm{~kg} / \mathrm{m}^{2}$ ) or 'obese' ( $\geq 30 \mathrm{~kg}$ / $\mathrm{m}^{2}$ ). Due to the higher risk of type 2 diabetes and cardiovascular disease among adults from Asian backgrounds at a BMI lower than $25 \mathrm{~kg} / \mathrm{m}^{2}$, lower thresholds for classifying overweight and obesity in South Asian adults were employed, where 'overweight' is considered $\geq 23$ to $<27.5$ $\mathrm{kg} / \mathrm{m}^{2}$ and 'obese' as $\geq 27.5 \mathrm{~kg} / \mathrm{m}^{2}$, based on National Institute for Healthcare Excellence guidelines. ${ }^{27}$

\section{Statistical methods}

Response to the parental concern question was missing for 82 children. All children for whom consent was obtained from a parent or guardian and who could stand unaided had their height and weight measured. ${ }^{21}$ Height was missing for 235 and weight was missing for 2345 -yearolds (both height and weight were missing for 218 5-yearolds). BMI was missing for 2456 parents. We used multiple imputation to estimate missing data on parental concern, child height and weight at age 5, and parental BMI, and built 20 imputed datasets using the weighted iterative chain algorithm, ${ }^{28}$ including all variables involved in the analysis steps under the assumption that missingness is at random (online supplementary table S2). All analyses were carried out on imputed datasets and sensitivity analyses on complete cases.

We used descriptive statistics (proportions and 95\% CIs) to assess the prevalence of parental concern overall, and by sex, ethnic background, child weight status and parental weight status. Similarly, we examined associations of child's weight status with parental concern by sex and ethnic background. We used logistic regression to estimate the unadjusted odds of a parent being concerned about their child being overweight in the future by child's ethnic group, sex, weight status and parental weight status (reported as ORs). We then mutually adjusted for child's ethnic background, sex, and child and parent weight status. We tested for interactions between the child's ethnic background and sex, and between child's ethnic background and weight status, and used Wald test statistics for these interaction terms to inform the final logistic regression model. We derived sex-specific and ethnic-specific ORs by multiplying the interaction term coefficient by the ethnicity coefficient and plotted these in a forest plot.

All analyses and percentages cited were performed in Stata and weighted to take account of survey design and to allow for potential biases in attrition by age 5 years, 
using the svyset command (Stata/SE V.15; StataCorp, College Station, Texas, USA).

\section{Ethics approval}

Approval for MCS was granted by the London Research Ethics Committees ${ }^{29}$ and no further approval was required for this secondary analysis.

\section{Patient and public involvement}

This research was done without patient or public involvement. Neither were invited to comment on the study design and were not consulted to develop relevant outcomes or interpret results.

\section{RESULTS}

\section{Sample characteristics}

Of 15039 children, $48.9 \%$ were girls, and $86.7 \%$ were from White and $6.1 \%$ from South Asian backgrounds (table 1). Parental concern about their child becoming overweight in the future was reported by $27.3 \%$ of parents (18.6\% 'a little concerned', 3.5\% 'concerned', $2.6 \%$ 'fairly concerned', $2.6 \%$ 'very concerned'), and this was more common among parents of girls than of boys (table 1).

\section{Parental concern}

Parental concern was strongly associated with child's BMI status and was more common among parents of children

Table 1 Sample characteristics and proportion of parents reporting parental concern

\begin{tabular}{|c|c|c|c|c|}
\hline & \multicolumn{2}{|c|}{ Sample characteristics* } & \multicolumn{2}{|c|}{ Parental concern } \\
\hline & $\%$ & $95 \% \mathrm{Cl}$ & $\%$ & $95 \% \mathrm{Cl}$ \\
\hline All & 100 & & 27.3 & 26.3 to 28.3 \\
\hline \multicolumn{5}{|l|}{ Sex } \\
\hline Boys & 51.1 & 50.2 to 52.1 & 24.1 & 22.8 to 25.4 \\
\hline Girls & 48.9 & 47.9 to 49.8 & 30.7 & 29.4 to 31.9 \\
\hline \multicolumn{5}{|l|}{ Child weight status $\dagger$} \\
\hline Healthy weight & 81.7 & 81.0 to 82.5 & 22.3 & 21.3 to 23.3 \\
\hline Overweight & 11.0 & 10.4 to 11.6 & 42.3 & 39.6 to 45.1 \\
\hline Obese & 6.6 & 6.1 to 7.1 & 66.2 & 62.9 to 69.6 \\
\hline \multicolumn{5}{|l|}{ Parent weight status $\ddagger$} \\
\hline Underweight & 3.1 & 2.7 to 3.4 & 15.4 & 11.1 to 19.6 \\
\hline Healthy weight & 52.8 & 51.5 to 54.0 & 22.7 & 21.5 to 23.9 \\
\hline Overweight & 27.2 & 26.2 to 28.2 & 29.9 & 28.0 to 31.9 \\
\hline Obese & 16.9 & 16.0 to 17.8 & 39.7 & 37.4 to 42.0 \\
\hline \multicolumn{5}{|l|}{ Ethnic background§ } \\
\hline White & 86.7 & 84.3 to 89.0 & 27.8 & 26.8 to 28.8 \\
\hline South Asian & 6.1 & 4.3 to 7.8 & 23.5 & 20.5 to 26.5 \\
\hline Indian & 1.8 & 1.3 to 2.4 & 28.5 & 23.2 to 33.7 \\
\hline Pakistani & 3.1 & 1.7 to 4.6 & 20.9 & 17.0 to 24.7 \\
\hline Bangladeshi & 1.1 & 0.5 to 1.6 & 22.6 & 16.8 to 28.4 \\
\hline Black & 2.8 & 1.8 to 3.8 & 24.9 & 19.6 to 30.1 \\
\hline Black Caribbean & 1.0 & 0.6 to 1.4 & 32.3 & 21.9 to 42.7 \\
\hline Black African & 1.6 & 1.0 to 2.3 & 20.1 & 15.5 to 24.7 \\
\hline Other Black & 0.2 & 0.1 to 0.2 & 25.7 & 7.3 to 44.1 \\
\hline Mixed and Other & 4.5 & 3.8 to 5.2 & 24.9 & 20.0 to 29.7 \\
\hline Other Asian & 0.6 & 0.3 to 0.8 & 30.7 & 17.7 to 43.8 \\
\hline Chinese and Other & 0.7 & 0.5 to 0.9 & 20.9 & 12.4 to 29.3 \\
\hline Mixed & 3.2 & 2.7 to 3.7 & 24.7 & 19.2 to 30.1 \\
\hline
\end{tabular}

*Total $\mathrm{n}=15039$.

†Child weight status based on ethnic-adjusted BMI and categorised according to UK90 clinical reference standard.

$\ddagger$ Parental weight status was categorised using BMI calculated from parental self-reported weight and height as follows: 'underweight' (BMI $\left.<18.5 \mathrm{~kg} / \mathrm{m}^{2}\right)$, 'healthy weight' $\left(\geq 18.5\right.$ to $\left.<25 \mathrm{~kg} / \mathrm{m}^{2}\right)$, 'overweight' $\left(\geq 25\right.$ to $\left.<30 \mathrm{~kg} / \mathrm{m}^{2}\right)$ or 'obese' $\left(\geq 30 \mathrm{~kg} / \mathrm{m}^{2}\right)$, except for South Asian adults where 'overweight' is $\geq 23$ to $<27.5 \mathrm{~kg} / \mathrm{m}^{2}$ and 'obese' is $\geq 27.5 \mathrm{~kg} / \mathrm{m}^{2}$.

$\S$ Ethnic background of the child was obtained from parental report at the first MCS interview and categorised using UK 2011 Census categories.

BMI, body mass index; MCS, Millennium Cohort Study. 
with overweight or obesity $(42.3 \%$ and $66.2 \%$, respectively) than among parents of children with a healthy weight (22.3\%; table 1). Similarly, parental concern was more likely to be reported by parents with overweight or obesity: $29.9 \%$ and $39.7 \%$, respectively, compared with parents with a healthy weight $(22.7 \%$; table 1$)$.

Parental concern was reported significantly less among parents of children from Pakistani (20.9\%) and Black African $(20.1 \%)$ backgrounds, compared with parents of children from White ethnic backgrounds (27.8\%; table 1).

\section{Overweight and obesity prevalence by ethnic background and sex}

At age 5, the prevalence of overweight and obesity was $11.0 \%$ and $6.6 \%$, respectively, with obesity more prevalent among boys (7.5\%) than girls (5.7\%) (table 2; parent weight status was positively associated with child weight status, see online supplementary table S3).

Within each ethnic group, most 5-year-old children were of healthy weight; however, children from South Asian backgrounds were more likely to have a BMI in the obese range than children from White backgrounds (table 2). There were some minor differences by sex, with boys from South Asian backgrounds and girls from Pakistani and Bangladeshi backgrounds more likely to have a BMI in the obese range than those from White backgrounds (table 2).

\section{Parental concern by ethnic background and sex}

Fewer parents of girls from Pakistani, Bangladeshi or Black African backgrounds reported parental concern relative to parents of girls from White backgrounds. These differences were not seen in boys (table 3 ).

Parental concern by weight status, ethnic background and sex Parental concern was reported for $73.4 \%$ of girls with obesity compared with $61.0 \%$ of boys with obesity (table 4).

Parental concern was reported by fewer parents of healthy weight, overweight and obese girls from South Asian backgrounds compared with parents of girls from White backgrounds (table 4). No differences in parental concern by weight status were observed between boys from different ethnic backgrounds (table 4).

\section{Logistic regression analyses}

After mutual adjustment for ethnic background, sex and child and parent weight status, parental concern was significantly less likely among children from Pakistani, Bangladeshi and Black African ethnic backgrounds. Parental concern was more likely among parents of overweight and obese children, or of girls, and among parents who themselves were overweight or obese (table 5 'Adjusted' model).

As the Wald test statistic for an interaction between sex and ethnic background was significant (online supplementary table S4), the final adjusted model included this interaction term (other interactions were not significant and were excluded from the final model; see online supplementary table $\mathrm{S} 4$ ). The sex-specific and ethnic-specific odds accounting for this interaction are shown in table 5 and figure 1, using White ethnic background as the reference category.

Parents of boys from Pakistani backgrounds were less likely to be concerned about their child's future risk of being overweight (figure 1), as were parents of girls from Pakistani, Bangladeshi, Black African, Mixed or Other ethnic backgrounds.

In the final model, parental concern about future childhood overweight was more likely among parents of children with overweight and obesity, and less likely among parents of children considered underweight, compared with parents of children with a healthy weight (figure 1). Parents who themselves had a BMI in the overweight or obese range were more likely, and those with a BMI considered underweight less likely, to report concern than those with a healthy weight (figure 1).

Adjusted ORs were similar for complete case analyses (with the exception of the interaction between female sex and Bangladeshi ethnic background; online supplementary table S5) and for BMI without ethnic adjustment (data not shown).

\section{DISCUSSION}

\section{Principal findings}

In this large nationally representative study, we found that parents of children from South Asian backgrounds were less likely to be concerned about their child's future overweight risk compared with those from White backgrounds. This was particularly so for girls from Pakistani and Bangladeshi backgrounds, and was independent of child and parent weight status. Furthermore, among our total sample of more than 15000 children, we confirmed associations between parental concern and child sex and weight status reported by others.

Increased understanding of the context in which people from different ethnic backgrounds report parental concern is important to inform the development of interventions to support parents and families to alter the weight trajectories of their children with overweight or obesity. This is especially important for children from South Asian backgrounds, given their higher absolute risk of obesity and greater metabolic sensitivity to its effects. Our findings make a significant contribution to the literature on parental concern. This is, to our knowledge, the first study to use a UK-wide nationally representative cohort to examine whether parental concern about future risk of overweight in their child varies by ethnic background.

\section{Strengths and limitations}

Strengths of our study include analyses based on a large, nationally representative cohort of children from diverse ethnic backgrounds, allowing examination of parental concern across 10 ethnic groups. Our findings are 


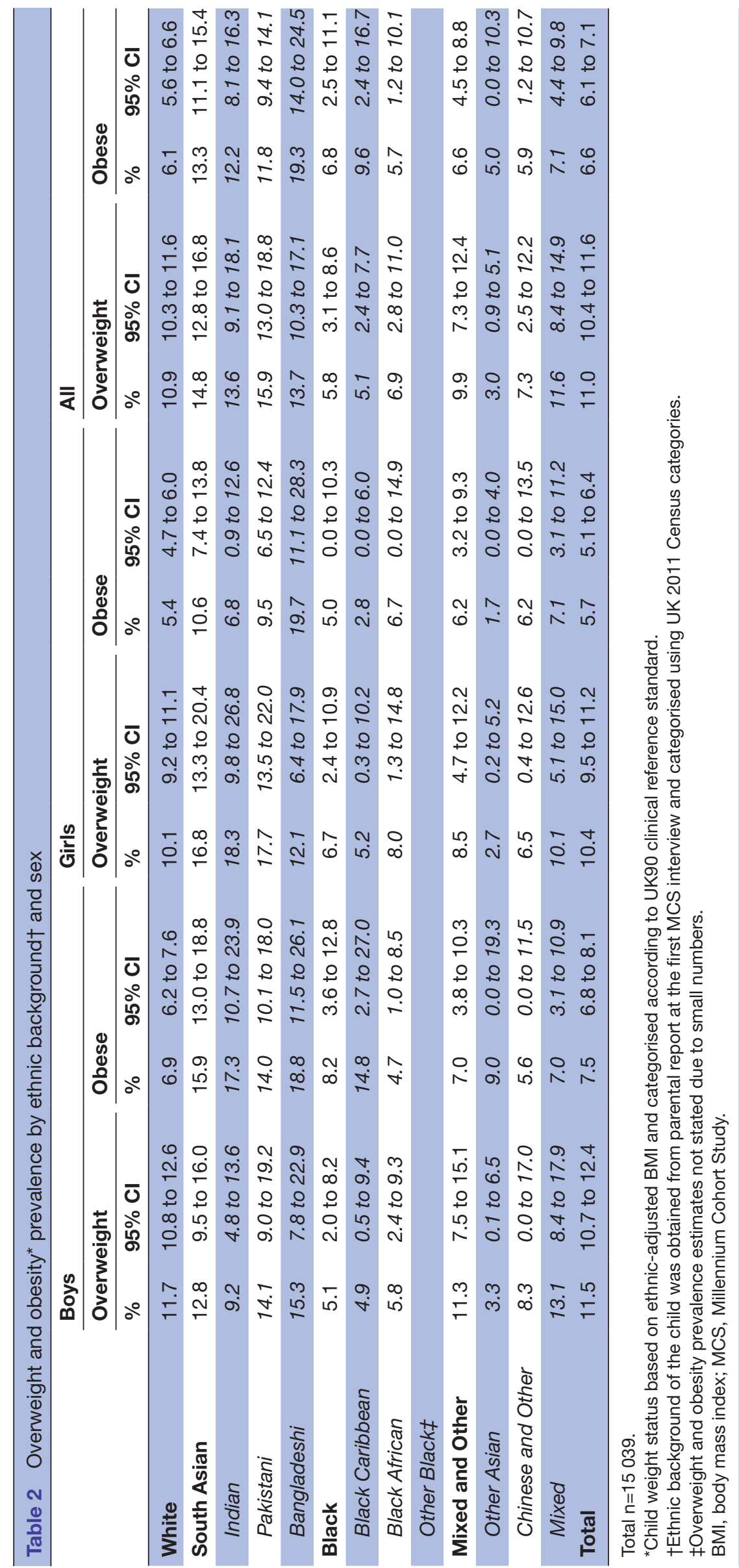


Table 3 Parental concern about future overweight risk at age 5 years by ethnic background* and sex

\begin{tabular}{|c|c|c|c|c|}
\hline & \multicolumn{2}{|c|}{ Boys } & \multicolumn{2}{|l|}{ Girls } \\
\hline & $\%$ & $95 \% \mathrm{Cl}$ & $\%$ & $95 \% \mathrm{Cl}$ \\
\hline White & 24.1 & 22.8 to 25.4 & 31.6 & 30.3 to 33.0 \\
\hline \multicolumn{5}{|l|}{ South Asian } \\
\hline Indian & 25.4 & 18.2 to 32.5 & 31.8 & 23.1 to 40.5 \\
\hline Pakistani & 21.8 & 15.4 to 28.3 & 19.9 & 14.6 to 25.3 \\
\hline Bangladeshi & 24.3 & 15.5 to 33.1 & 21.1 & 13.0 to 29.1 \\
\hline \multicolumn{5}{|l|}{ Black } \\
\hline Black Caribbean & 32.1 & 20.3 to 43.9 & 32.5 & 19.3 to 45.8 \\
\hline Black African & 19.2 & 11.4 to 27.1 & 21.1 & 15.6 to 26.7 \\
\hline Other Black & 26.3 & 3.1 to 49.5 & 24.8 & 0.0 to 54.0 \\
\hline \multicolumn{5}{|l|}{ Mixed and Other } \\
\hline Other Asian & 35.7 & 19.6 to 51.8 & 26.5 & 9.9 to 43.2 \\
\hline $\begin{array}{l}\text { Chinese and } \\
\text { Other }\end{array}$ & 20.2 & 7.6 to 32.8 & 21.5 & 8.6 to 34.3 \\
\hline Mixed & 23.7 & 16.2 to 31.3 & 25.7 & 19.3 to 32.0 \\
\hline
\end{tabular}

Total $\mathrm{N}=15039$.

${ }^{*}$ Ethnic background of the child was obtained from parental report at the first Millennium Cohort Study interview and categorised using UK 2011 Census categories.

generalisable to the UK reflecting the nationally representative nature of the MCS: both the prevalence of overweight and obesity and the proportion of children from each ethnic background at age 5 in this cohort are similar to that reported in Public Health England's National Child Measurement Programme (NCMP) for the 2006/2007 academic year, when most children included in this study were aged 5 years. ${ }^{30} 31$

We used robust statistical methods including imputation of missing data and use of survey weights to account for survey design and to allow for biases in attrition. We used a clinical definition of overweight and obesity that indicates the need for clinical weight management support, and applied ethnic-specific BMI adjustment for more accurate assessment of body fatness in children from South Asian and Black ethnic backgrounds. While this method of adjusting children's BMI is not currently employed in the NCMP, which may make comparisons with other studies less straightforward, analyses without ethnic adjustment produced similar findings.

We were able to adjust for a number of covariates in our analysis including those shown previously to be strongly associated with parental concern, including parental and child weight status (the latter based on objective measurements). Responses to the question eliciting parental concern are unlikely to be influenced by the MCS weight measurement as this question was asked before the child was weighed, and furthermore no interpretation or categorisation of MCS BMI was provided in the feedback to parents. ${ }^{29}$

Although it is possible that some children may have been recently weighed either at home, in clinical care or in school as part of the NCMP, information on the timing of this in relation to the MCS interview, or the feedback given to parents, is unavailable. The MCS interview did not ask parents about their perception of their child's weight status at age 5 , and consequently we were unable to adjust for this in our final model. Furthermore, given the cross-sectional design of this study, we are unable to

Table 4 Parental concern about future overweight risk at age 5 years, by child weight status* at age 5

\begin{tabular}{|c|c|c|c|c|c|c|c|c|c|c|}
\hline & \multicolumn{10}{|c|}{ Proportion of parents reporting parental concern } \\
\hline & \multicolumn{2}{|c|}{ White } & \multicolumn{2}{|c|}{ South Asian } & \multicolumn{2}{|c|}{ Black } & \multicolumn{2}{|c|}{ Mixed and Other } & \multicolumn{2}{|l|}{ All } \\
\hline & $\%$ & $95 \% \mathrm{Cl}$ & $\%$ & $95 \% \mathrm{Cl}$ & $\%$ & $95 \% \mathrm{Cl}$ & $\%$ & $95 \% \mathrm{Cl}$ & $\%$ & $95 \% \mathrm{Cl}$ \\
\hline Healthy weight & 22.8 & 21.8 to 23.8 & 16.9 & 14.5 to 19.3 & 21.5 & 15.5 to 27.6 & 19.5 & 14.6 to 24.4 & 22.3 & 21.3 to 23.3 \\
\hline Overweight & 43.8 & 40.8 to 46.8 & 28.4 & 22.1 to 34.8 & 30.1 & 6.9 to 53.3 & 39.8 & 25.3 to 54.3 & 42.3 & 39.6 to 45.1 \\
\hline Healthy weight & 19.6 & 18.3 to 21.0 & 16.8 & 13.5 to 20.2 & 18.1 & 13.0 to 23.2 & 17.6 & 11.3 to 23.8 & 19.3 & 18.0 to 20.6 \\
\hline Overweight & 34.2 & 30.1 to 38.3 & 25.9 & 16.4 to 35.4 & 46.7 & 20.4 to 72.9 & 46.6 & 25.9 to 67.3 & 34.5 & 30.7 to 38.3 \\
\hline Obese & 61.4 & 56.1 to 66.7 & 51.4 & 41.6 to 61.2 & 55.6 & 31.8 to 79.3 & 70.7 & 47.9 to 93.4 & 61.0 & 56.6 to 65.4 \\
\hline \multicolumn{11}{|l|}{ Girls } \\
\hline
\end{tabular}

Total $n=15039$.

*Underweight groups omitted due to small numbers. Child weight status based on ethnic-adjusted body mass index and categorised according to UK90 clinical reference standard. 


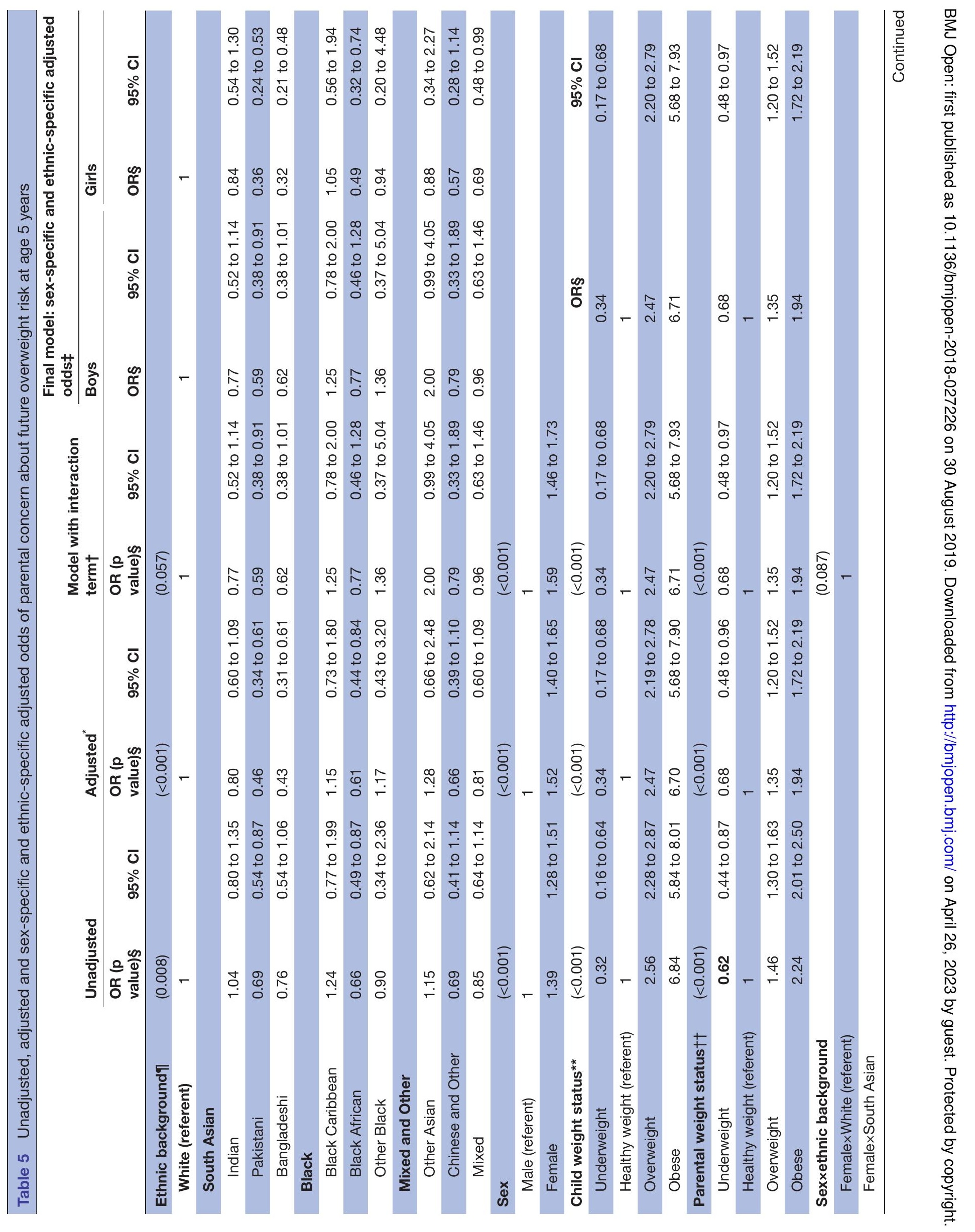



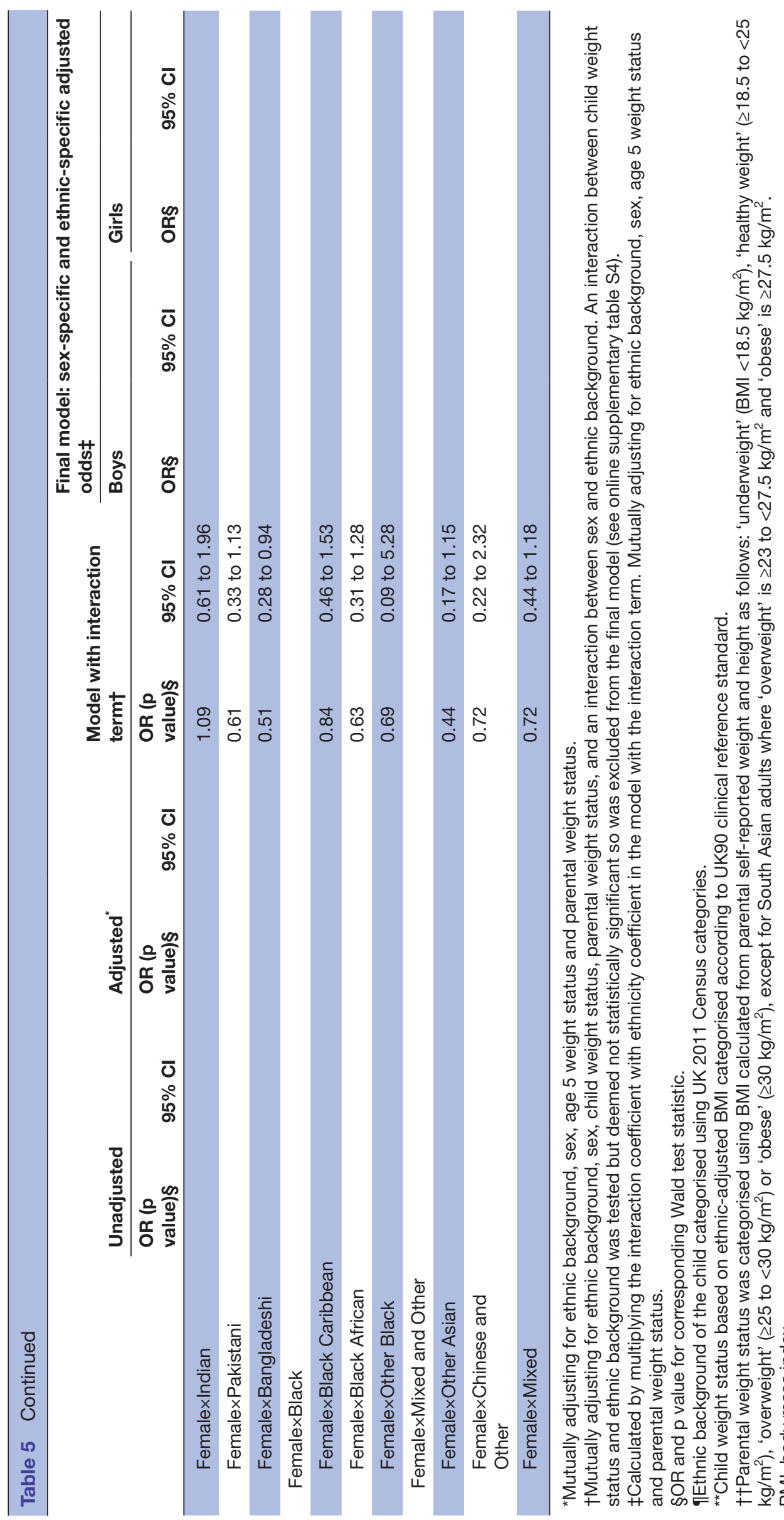

을 을

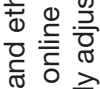

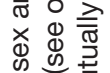

क $\frac{\overline{0}}{2}$

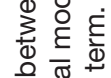

व

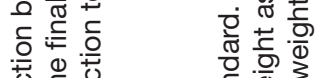

प्ष

离哜竞

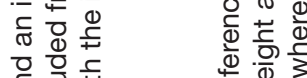

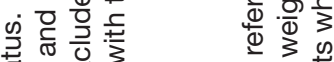

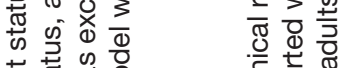

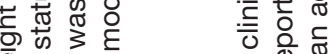

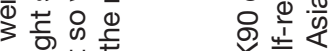

ब.
ब.

ब

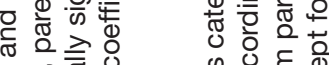

की

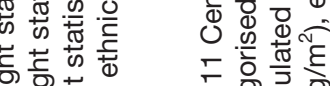

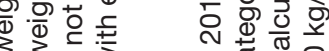

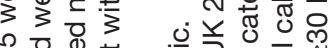

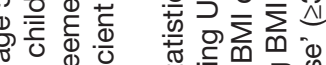

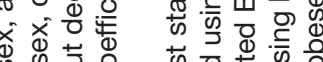

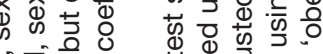

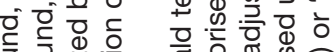

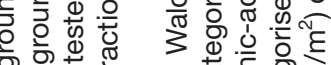

गे

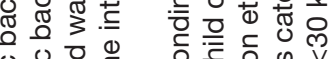

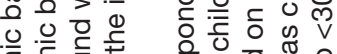

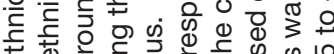

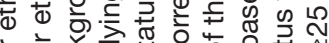

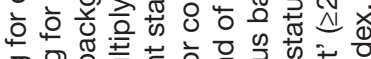

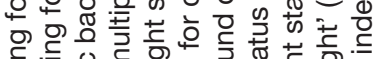

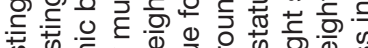

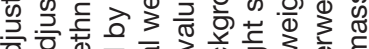

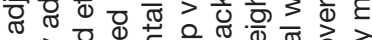

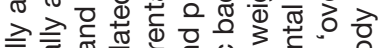

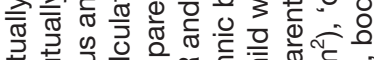

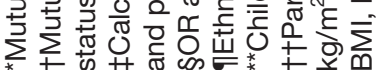




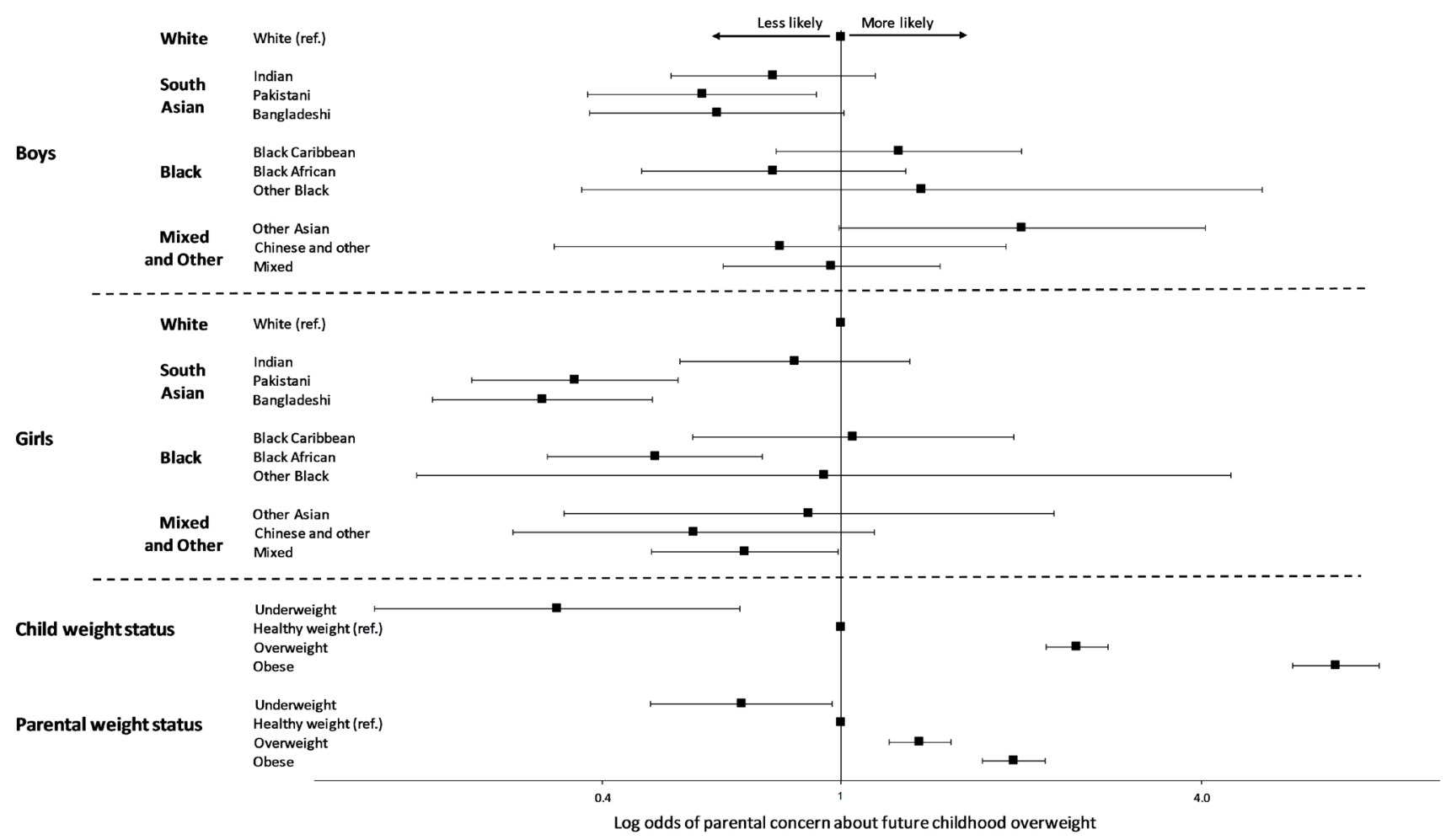

Figure 1 Adjusted odds of parental concern about future childhood overweight (mutually adjusted for ethnic background, sex, child weight status, parent weight status, and an interaction between sex and ethnic background).

draw any conclusions about the temporal relationship between parental concern and child weight status. Since the majority of main respondents were natural mothers, our findings may not be generalisable to fathers or other parents.

As one in seven children in this study were from Black, South Asian and Other ethnic backgrounds, we were able to examine parental concern across all major ethnic groups; however, absolute numbers for some groups were small, resulting in greater uncertainty for these estimates.

We used lower thresholds for overweight and obesity to categorise BMI in adults from South Asian backgrounds to reflect the higher risk of type 2 diabetes and cardiovascular disease at lower levels of BMI experienced among these adults. ${ }^{27}$ Although parental height and weight were self-reported, this is considered a reliable measure in epidemiological studies. ${ }^{32}{ }^{33}$ Furthermore, at present there are no validated algorithms for the adjustment of BMI for children from Mixed and Other ethnic backgrounds, so no adjustments were made for these children in our analyses. Although we lacked statistical power to evaluate all subcategories of parental concern, we used the approach others have taken using this instrument and dichotomised parental concern into 'concern' or 'no concern' in order to produce robust estimates when examining parental concern by sex and ethnic background. ${ }^{1214-16}$

\section{Other studies}

There are, to our knowledge, no other published reports examining ethnic variation in parental concerns about their child's future risk of becoming overweight using a UK-wide nationally representative cohort of children. Our finding of less parental concern among parents of girls from Black African backgrounds is similar to that reported for parents from Black Somali backgrounds in Liverpool, ${ }^{8}$ but not consistent with those from a regional study which observed greater parental concern among parents from Black Afro-Caribbean backgrounds living in London. ${ }^{17}$

The explanations for our main finding that there is variation by ethnic background in parental reported concern about their child's future risk of becoming overweight warrant further investigation. This finding may reflect differences in awareness of children's weight status or perceptions of childhood weight and size among parents from different ethnic backgrounds. However, it may be more useful to explore the wider context and barriers which children and their families from different ethnic backgrounds face in negotiating healthy or 'ideal' weight so that interventions can be considered which reflect the diverse ethnic backgrounds of children with obesity in the UK.

Many parents are unable to identify overweight or obesity in their children, ${ }^{15} 3435$ with the majority of parents of children with a BMI in the overweight or obese 
range underestimating their child's weight status, ${ }^{12}{ }^{36}$ a finding replicated in numerous high-income countries across the world. ${ }^{353738}$ While there is some evidence that recognition of overweight or obesity is difficult among adults from South Asian backgrounds, ${ }^{39}$ the reasons for this remain unclear and similar studies in children are lacking.

While parental recognition of child overweight or obesity can be helped by presenting them with child age-specific and sex-specific body images, ${ }^{40}$ these have not been tested among parents from different ethnic backgrounds. Furthermore, we did not find any evidence to suggest that parental concern about child future overweight risk among children from different ethnic backgrounds varied by objectively measured child weight status.

Qualitative research provides important contextual information about South Asian parents and their extended families. Pallan et al have highlighted the importance of intergenerational influences on child diet and perception of their weight status, suggesting that fatness may signal health and that provision of abundant food may symbolise parental/carer affection for the child. ${ }^{41}$ This may be important for families relying on grandparents for informal childcare, and multigenerational households where meals are communally prepared and eaten. ${ }^{41}{ }^{42}$ For example, studies of women from Pakistan living in North West England and an ethnically diverse sample of families in London have both reported that in these groups, familial expectations to maintain traditional home-cooking procedures are obstacles to changing food preparation and eating practices. ${ }^{42}$ Similarly, qualitative research involving women from Somalia living in Liverpool found that many women felt restricted in their efforts to live healthier lifestyles by older relatives' perspectives which promote increased weight, although this study did not focus on the influence of the home environment on their child's weight status, ${ }^{43}$ highlighting differences between people from different ethnic backgrounds.

While there is evidence that acculturation can alter maternal health behaviours with the adoption of potentially less healthy behaviours by migrants over time, ${ }^{44}$ we did not set out to examine structural barriers or acculturation among migrants in this study and further research to explore intergenerational variation in parental concern about future childhood overweight is required.

Our finding that a greater proportion of parents of girls compared with parents of boys from White backgrounds were concerned about their child becoming overweight in the future is consistent with findings from other UK studies of predominantly White populations ${ }^{13-15}$ and with one from Australia. ${ }^{16}$ This may reflect societal expectations of 'ideal' body shapes for boys and girls ${ }^{14}$ whereby girls are expected to be slight or petite, and boys to be bigger, stronger or more muscular. ${ }^{45}$ Findings from a qualitative study interviewing parents of preschool-aged children in America suggest that childhood overweight is normalised through the use of euphemistic terms like 'cute baby fat' or 'podge', ${ }^{46}$ and discussions of body size relate to how 'big', 'strong' or 'muscular' the child is. ${ }^{47}$ Other studies have suggested that parents do not worry about their child's weight status because they believe their child participates in an appropriate level of physical activity and/or eats a balanced or healthy diet. ${ }^{47} 48$

Given these accounts, parents from different ethnic backgrounds may experience social contexts where monitoring child weight is not a priority, particularly in environments where higher weight is a signal of wellness, health and affection for the child. Similarly, given that people from ethnic minority backgrounds, particularly from Pakistan and Bangladesh, are more likely than White British people to live in the most deprived areas in England, ${ }^{49}$ it is possible parents prioritise providing for their family over parental concern about future childhood overweight, a less immediate concern. This view is supported by literature which suggests that the future may be perceived differently depending on personal circumstances, such that concepts of 'public health futures' are not applicable to all individuals. ${ }^{50}$

Our finding that concern was reported more often for children with overweight and obesity is consistent with previously published reports. ${ }^{9}{ }^{12-15}$ Our findings are similar to those of Carnell et alwho used the same question and response scale but did not examine the influence of ethnicity on this association. ${ }^{12}$ Parents may be better able to identify their child's weight status at the extreme end of obesity ${ }^{1415}$ indicating that, to some extent, parents are aware of overweight in their children. Inability to assess correctly their child's weight may be a barrier to prevention of childhood obesity ${ }^{131451}$ since lifestyle changes are not initiated ${ }^{3652}$; however, Carnell et al have argued that parental concern is a more sensitive indicator of parental awareness of than parental identification of a child's weight status.

The temporality of this relationship, however, remains unclear as our study was cross-sectional. While it seems plausible that parents are more likely to report concern because their children are already overweight, a range of studies, predominantly from Australia ${ }^{53-55}$ and the $\mathrm{USA}^{56-60}$ as well as from the $\mathrm{UK}^{61}$ and Sweden, ${ }^{62}$ have proposed that parents reporting concern about their child becoming overweight might be more likely to engage in behaviours such as restrictive feeding, where children's food is controlled and limited.

Longitudinal research has suggested that restrictive feeding practices can result in child weight gain. A prospective study of Australian children aged 2 years suggests restrictive feeding practices lead to obesogenic behaviours such as overeating, ${ }^{63}$ while in the USA a study of children 5 to 7 years old showed a positive association between restrictive feeding and additional weight gain among children at risk of obesity. ${ }^{64}$ Two further longitudinal studies in the USA showed restrictive feeding practices were associated with increased eating in the absence of hunger among girls aged 5 to 9 years. ${ }^{656}$ 
With this in mind and given the cross-sectional nature of our study, our findings require careful interpretation: while it is possible that parental concern is a response to child overweight, it remains that child overweight could be in part driven by parental concern and associated feeding practices.

Whether parental feeding practices vary by ethnic background is largely unknown, ${ }^{67}$ but remains an important research question particularly as it has been suggested that there may be benefits to restrictive feeding for older, more overweight children but less so for younger, healthy weight children who are yet to develop their eating behaviours. ${ }^{67}$ One cross-sectional study comparing feeding practices in Germany and Britain found that parents from Black Afro-Caribbean backgrounds living in Britain were more likely to use restrictive feeding practices than parents from White backgrounds living in either Britain or Germany, and this was associated with higher child BMI. ${ }^{68}$ Further research is needed to understand how social context and ethnic backgrounds might influence parents' feeding practices.

\section{Implications for policy and practice}

Our study has implications for practice and research. Our cross-sectional analyses confirmed a strong positive association between the child's current weight status and parental concern, suggesting parents of children with a BMI in the overweight and obese range are more likely than other parents to be concerned about their child's future overweight risk. This is important, given the suggestion that appropriate parental concern is vital for effective parental engagement with obesity intervention programmes $^{7}$ and positive behaviour change. ${ }^{6}$ Further research is needed to determine whether parental concern is associated with healthier weight trajectories, as well as to understand how feedback given to parents about their child's weight status from the NCMP can be appropriately and accurately conveyed to parents from different ethnic backgrounds.

Our study also has implications in particular for targeted interventions aimed at childhood obesity prevention and management. Parents from particular ethnic backgrounds at higher risk of obesity are less likely to express concern about future childhood overweight, particularly so for girls. This needs to be taken into account in developing ethnically sensitive interventions for weight management of children with obesity in multiethnic populations. As with all complex interventions, these need to be informed by qualitative studies to elucidate the factors underlying these novel observed differences in rates of parental concern among participants from different ethnic backgrounds, and to aid their interpretation.

\section{CONCLUSION}

In summary, we have found that, in contrast to our original hypothesis and after taking into account child and parental weight status, parents of children from South
Asian ethnic backgrounds who are at higher risk of childhood obesity and its adverse consequences are less likely to report concern for their child's future overweight risk, particularly for their daughters. These novel insights are of importance to the UK population, where the highest risk of obesity is observed in individuals and communities from these backgrounds.

Acknowledgements The co-operation of the Millennium Cohort Study participating families is gratefully acknowledged. The authors are grateful to Mohammed Hudda, Professor Peter Whincup and colleagues at St. George's University of London, Population Health Research Institute, for sharing their algorithms for ethnic-specific BMI adjustment.

Contributors NF and CD conceptualised and designed the analysis. NF carried out the literature search, conducted and interpreted the analyses, generated tables and figures, and drafted the initial manuscript. CD contributed to the interpretation of analyses, and reviewed and revised the manuscript. All authors were involved in writing the paper and had final approval of the submitted and published versions.

Funding This research was funded by a grant from Barts Charity ref: MGU0419. The authors are grateful to the Centre for Longitudinal Studies, UCL Institute of Education and the UK Data Service.

Competing interests None declared.

Patient consent for publication Not required.

Ethics approval Approval for MCS1 was granted by South West MREC MREC/01/6/19. Approval for MCS2 was granted by London MREC MREC/03/2/022. Approval for MCS3 was granted by London MREC Committee. 05/MRE02/46. Approval for MCS4 was granted by Yorkshire MREC 07/MRE03/32. Approval for MCS5 was granted by Yorkshire and The Humber-Leeds East 11/YH/0203.

Provenance and peer review Not commissioned; externally peer reviewed.

Data availability statement Data are available in a public, open-access repository.

Open access This is an open access article distributed in accordance with the Creative Commons Attribution Non Commercial (CC BY-NC 4.0) license, which permits others to distribute, remix, adapt, build upon this work non-commercially, and license their derivative works on different terms, provided the original work is properly cited, appropriate credit is given, any changes made indicated, and the use is non-commercial. See: http://creativecommons.org/licenses/by-nc/4.0/.

\section{REFERENCES}

1. NHS Digital. National Child Measurement Programme, 2016-17, 2017. Available: https://digital.nhs.uk/data-and-information/ publications/statistical/national-child-measurement-programme/ national-child-measurement-programme-england-2016-17

2. Hudda MT, Nightingale CM, Donin AS, et al. Patterns of childhood body mass index (BMI), overweight and obesity in South Asian and black participants in the English National child measurement programme: effect of applying BMI adjustments standardising for ethnic differences in BMl-body fatness associations. Int $\mathrm{J}$ Obes 2018;42:662-70.

3. NHS Digital. Health survey for England 2004: the health of ethnic minorities NHS digital website: NHS digital, 2006. Available: https:// digital.nhs.uk/catalogue/PUB01209

4. Tillin T, Hughes AD, Mayet J, et al. The relationship between metabolic risk factors and incident cardiovascular disease in Europeans, South Asians, and African Caribbeans: SABRE (Southall and Brent Revisited) - a prospective population-based study. J Am Coll Cardiol 2013;61:1777-86.

5. Nightingale CM, Rudnicka AR, Owen CG, et al. Influence of adiposity on insulin resistance and glycemia markers among U.K. children of South Asian, black African-Caribbean, and white European origin: child heart and health study in England. Diabetes Care 2013;36:1712-9.

6. Moore LC, Harris CV, Bradlyn AS. Exploring the relationship between parental concern and the management of childhood obesity. Matern Child Health J 2012;16:902-8.

7. Gregori D, Hochdorn A, Azzolina D, et al. Does love really make mothers blind? A large transcontinental study on mothers' awareness about their children's weight. Obesity 2018;26:1211-24. 
8. Trigwell J, Watson PM, Murphy RC, et al. Ethnic differences in parental attitudes and beliefs about being overweight in childhood. Health Educ J 2014;73:179-91.

9. Lampard AM, Byrne SM, Zubrick SR, et al. Parents' concern about their children's weight. Int J Pediatr Obes 2008;3:84-92.

10. Peyer KL, Welk G, Bailey-Davis L, et al. Factors associated with parent concern for child weight and parenting behaviors. Child Obes 2015;11:269-74.

11. Pesch MH, Rizk M, Appugliese DP, et al. Maternal concerns about children overeating among low-income children. Eat Behav 2016;21:220-7.

12. Carnell $\mathrm{S}$, Edwards $\mathrm{C}$, Croker $\mathrm{H}$, et al. Parental perceptions of overweight in 3-5 Y olds. Int J Obes 2005;29:353-5.

13. Jeffery AN, Voss LD, Metcalf BS, et al. Parents' awareness of overweight in themselves and their children: cross sectional study within a cohort (EarlyBird 21). BMJ 2005;330:23-4

14. Jeffery AN, Metcalf BS, Hosking J, et al. Awareness of body weight by mothers and their children: repeated measures in a single cohort (EarlyBird 64). Child Care Health Dev 2015;41:434-42.

15. Parkinson KN, Reilly JJ, Basterfield L, et al. Mothers' perceptions of child weight status and the subsequent weight gain of their children: a population-based longitudinal study. Int J Obes 2017:41:801-6.

16. Campbell MW-C, Williams J, Hampton A, et al. Maternal concern and perceptions of overweight in Australian preschool-aged children Med J Aust 2006;184:274-7.

17. Gu C, Warkentin S, Mais LA, et al. Ethnic differences in parental feeding behaviors in UK parents of preschoolers. Appetite 2017;113:398-404.

18. Public Health England. Changes in the weight status of children between the first and final years of primary school. A longitudinal analysis of data from the National Child Measurement Programme in four local authorities in England between 2006/07 and 2014/15, 2017.

19. Mead E, Batterham AM, Atkinson G, et al. Predicting future weight status from measurements made in early childhood: a novel longitudinal approach applied to millennium cohort study data. Nutr Diabetes 2016;6:e200.

20. Bhopal R. Glossary of terms relating to ethnicity and race: for reflection and debate. J Epidemiol Community Health 2004;58:441-5.

21. Chaplin Gray J, Gatenby R, Simmonds N. Millennium Cohort Study sweep 3 technical report. Institute of Education, 2009.

22. NHS Digital. Validation of national child measurement programme data; 2016. http://webarchive.nationalarchives.gov.uk/ 20180328130852tf/http://content.digital.nhs.uk/media/16230/ Validation-of-National-Child-Measurement-Programme-Data/pdf/ Validation_Principle_and_Rules.pdf/

23. Hudda MT, Nightingale CM, Donin AS, et al. Body mass index adjustments to increase the validity of body fatness assessment in UK black African and South Asian children. Int J Obes 2017;41:1048-55.

24. Scientific Advisory Committee on Nutrition, Royal College of Paediatrics and Child Health. Consideration of issues around the use of BMI centile thresholds for defining underweight, overweight and obesity in children aged 2-8 years in the UK, 2012

25. Harlow Printing Limited. LMS growth Microsoft Excel add-in software. Available: http://www.healthforallchildren.com/shop-base/ shop/software/lmsgrowth/

26. Cole TJ, Freeman JV, Preece MA. Body mass index reference curves for the UK, 1990. Arch Dis Child 1995;73:25-9.

27. National Institute for Health Care Excellence. BMI: preventing ill health and premature death in black, Asian and other minority ethnic groups. Public Health Guidance [Internet], 2013. Available: https://www.nice.org.uk/guidance/ph46/chapter/1Recommendations

28. van-Buuren S, Groothuis-Oudshoorn K. mice: Multivariate Imputation by Chained Equations in R. J Stat Softw 2011;45.

29. Millennium Cohort Study. Ethical review and consent, 2014.

30. Pearce A, Rougeaux E, Law C. Disadvantaged children at greater relative risk of thinness (as well as obesity): a secondary data analysis of the England National Child Measurement Programme and the UK Millennium Cohort Study. Int J Equity Health 2015;14:61.

31. Department of Health. The Infomation Centre. National Child Measurement Programme: 2006/07 school year, headline results, 2008.

32. Cairns BJ, Liu B, Clennell S, et al. Lifetime body size and reproductive factors: comparisons of data recorded prospectively with self reports in middle age. BMC Med Res Methodol 2011;11.

33. Spencer EA, Appleby PN, Davey GK, et al. Validity of self-reported height and weight in 4808 EPIC-Oxford participants. Public Health Nutr 2002;5:561-5.
34. Wake M, Canterford L, Hardy P, et al. At what BMI are parents of preschoolers concerned? National cross-sectional study. Int J Pediatr Obes 2011;6:499-501.

35. Regber S, Novak M, Eiben G, et al. Parental perceptions of and concerns about child's body weight in eight European countries-the IDEFICS study. Pediatr Obes 2013;8:118-29.

36. Conolly A. Health survey for England 2015 children's body mass index, overweight and obesity. NatCen: NHS Digital, 2016.

37. Howe CJ, Alexander G, Stevenson J. Parents' underestimations of child weight: implications for obesity prevention. $J$ Pediatr Nurs 2017;37:57-61

38. McDonald SW, Ginez HK, Vinturache AE, et al. Maternal perceptions of underweight and overweight for 6-8 years olds from a Canadian cohort: reporting weights, concerns and conversations with healthcare providers. BMJ Open 2016;6:e012094.

39. Eastwood SV, Tillin T, Dehbi H-M, et al. Ethnic differences in associations between fat deposition and incident diabetes and underlying mechanisms: the sabre study. Obesity 2015;23:699-706.

40. Jones AR, Tovée MJ, Cutler LR, et al. Development of the MapMe intervention body image scales of known weight status for 4-5 and 10-11 year old children. J Public Health 2018;40:582-90.

41. Pallan M, Parry J, Cheng KK, et al. Development of a childhood obesity prevention programme with a focus on UK South Asian communities. Prev Med 2013;57:948-54.

42. Rawlins E, Baker G, Maynard M, et al. Perceptions of healthy eating and physical activity in an ethnically diverse sample of young children and their parents: the DEAL prevention of obesity study. $J$ Hum Nutr Diet 2013;26:132-44.

43. Gardner K, Salah S, Leavey C, et al. The perfect size: perceptions of and influences on body image and body size in young Somali women living in Liverpool-a qualitative study. Diversity and Equality in Health and Care 2010;7.

44. Hawkins S, Lamb K, Cole TJ, et al. Influence of moving to the UK on maternal health behaviours: prospective cohort study. BMJ Global Health 2008;336:1052-5.

45. Lundahl A, Kidwell KM, Nelson TD. Parental underestimates of child weight: a meta-analysis. Pediatrics 2014;133:e689-703.

46. Eli K, Howell K, Fisher PA, et al. "A little on the heavy side": a qualitative analysis of parents' and grandparents' perceptions of preschoolers' body weights: Table 1. BMJ Open 2014;4:e006609.

47. Jain A, Sherman SN, Chamberlin DLA, et al. Why don't low-income mothers worry about their preschoolers being overweight? Pediatrics 2001:107:1138-46.

48. Nnyanzi LA, Summerbell CD, Ells L, et al. Parental response to a letter reporting child overweight measured as part of a routine national programme in England: results from interviews with parents. BMC Public Health 2016;16:846.

49. Ministry of Housing Communities and Local Government. People living in deprived neighbourhoods England, 2018. Available: https://www.ethnicity-facts-figures.service.gov.uk/ british-population/demographics/people-living-in-deprivedneighbourhoods/latest

50. Warin M, Zivkovic T, Moore V, et al. Short horizons and obesity futures: disjunctures between public health interventions and everyday temporalities. Soc Sci Med 2015;128:309-15.

51. Park MH, Falconer CL, Croker $\mathrm{H}$, et al. Predictors of health-related behaviour change in parents of overweight children in England. Prev Med 2014;62:20-4

52. Parry LL, Netuveli G, Parry J, et al. A systematic review of parental perception of overweight status in children. J Ambul Care Manage 2008;31:253-68.

53. Gregory JE, Paxton SJ, Brozovic AM. Pressure to eat and restriction are associated with child eating behaviours and maternal concern about child weight, but not child body mass index, in 2- to 4-year-old children. Appetite 2010;54:550-6.

54. Haines J, Downing KL, Tang L, et al. Associations between maternal concern about child's weight and related behaviours and maternal weight-related parenting practices: a cross-sectional study. Int $J$ Behav Nutr Phys Act 2018;15.

55. Crouch P, O'Dea JA, Battisti R. Child feeding practices and perceptions of childhood overweight and childhood obesity risk among mothers of preschool children. Nutr Diet 2007:64:151-8

56. Branch JM, Appugliese DP, Rosenblum KL, et al. Feeding and mealtime correlates of maternal concern about children's weight. $J$ Nutr Educ Behav 2017;49:490-6.

57. May AL, Donohue M, Scanlon KS, et al. Child-feeding strategies are associated with maternal concern about children becoming overweight, but not children's weight status. J Am Diet Assoc 2007;107:1167-74.

58. Swyden K, Sisson SB, Morris AS, et al. Association between maternal stress, work status, concern about child weight, and 
restrictive feeding practices in preschool children. Matern Child Health J 2017;21:1349-57.

59. Seburg EM, Kunin-Batson A, Senso MM, et al. Concern about child weight among parents of children at-risk for obesity. Health Behav Policy Rev 2014;1:197-208.

60. Swyden K, Sisson SB, Lora K, et al. Relationship between parental perception and concern for child weight and influence on obesogenic parenting practices. Adv in Pediatr Res 2015;2:1-9.

61. Webber L, Hill C, Cooke L, et al. Associations between child weight and maternal feeding styles are mediated by maternal perceptions and concerns. Eur J Clin Nutr 2010;64:259-65.

62. Ek A, Sorjonen K, Eli K, et al. Associations between parental concerns about preschoolers' weight and eating and parental feeding practices: results from analyses of the Child Eating Behavior Questionnaire, the Child Feeding Questionnaire, and the Lifestyle Behavior Checklist. PLoS One 2016;11:e0147257.
63. Rodgers RF, Paxton SJ, Massey R, et al. Maternal feeding practices predict weight gain and obesogenic eating behaviors in young children: a prospective study. Int J Behav Nutr Phys Act 2013;10.

64. Faith MS, Berkowitz RI, Stallings VA, et al. Parental feeding attitudes and styles and child body mass index: prospective analysis of a gene-environment interaction. Pediatrics 2004;114:e429-36.

65. Birch LL, Fisher JO, Davison KK. Learning to overeat: maternal use of restrictive feeding practices promotes girls' eating in the absence of hunger. Am J Clin Nutr 2003;78:215-20.

66. Fisher JO, Birch LL. Eating in the absence of hunger and overweight in girls from 5 to 7 Y of age. Am J Clin Nutr 2002;76:226-31.

67. Faith MS, Kerns J. Infant and child feeding practices and childhood overweight: the role of restriction. Matern Child Nutr 2005;1:164-8.

68. Blissett $\mathrm{J}$, Bennett C. Cultural differences in parental feeding practices and children's eating behaviours and their relationships with child BMI: a comparison of Black Afro-Caribbean, White British and White German samples. Eur J Clin Nutr 2013;67:180-4. 